\title{
Factors Associated with Treatment Compliance in Hypertension in Southwest Nigeria
}

\author{
Pauline E. Osamor' and Bernard E. Owumi² \\ 'Department of Sociology, Bowen University, Iwo, Osun State, Nigeria and \\ ${ }^{2}$ Department of Sociology, University of Ibadan, Ibadan, Oyo State, Nigeria
}

\begin{abstract}
Hypertension is an important condition among adults, affecting nearly one billion people worldwide. Treatment with appropriate medication is a key factor in the control of hypertension and reduction in associated risk of complications. However, compliance with treatment is often sub-optimal, especially in developing countries. The present study investigated the factors associated with self-reported compliance among hypertensive subjects in a poor urban community in southwest Nigeria. This community-based crosssectional study employed a survey of a convenience sample of 440 community residents with hypertension and eight focus-group discussions (FGDs) with a subset of the participants. Of the 440 hypertensive respondents, $65.2 \%$ were women, about half had no formal education, and half were traders. Over $60 \%$ of the respondents sought care for their condition from the hospital while only $5 \%$ visited a chemist or a patent medicine vendor (PMV). Only 51\% of the subjects reported high compliance. Factors associated with high self-reported compliance included: regular clinic attendance, not using non-Western prescription medication, and having social support from family members or friends who were concerned about the respondent's hypertension or who were helpful in reminding the respondent about taking medication. Beliefs about cause of hypertension were not associated with compliance. The findings of the FGDs showed that the respondents believed hypertension is curable with the use of both orthodox and traditional medicines and that a patient who 'feels well' could stop using antihypertensive medication. It is concluded that treatment compliance with antihypertensive medication remains sub-optimal in this Nigerian community. The factors associated with high self-reported compliance were identified. More research is needed to evaluate how such findings can be used for the control of hypertension at the community level.
\end{abstract}

Key words: Adherence; Cardiovascular diseases; Community-based studies; Compliance; Cross-sectional studies; Hypertension; Nigeria

\section{INTRODUCTION}

Hypertension is an overwhelming global challenge, which ranks third as a means of reduction in disability-adjusted life-years (1). It affects approximately one billion people worldwide ( $4.5 \%$ of the current global burden of disease)-340 million of these in economically-developed and 340 million in economically-developing countries. Annually, it causes 7.1 million (or one-third of) global preventable premature deaths $(2,3)$. Due to the fact that hypertension is one of the most important modifi-

Correspondence and reprint requests should be addressed to:

Dr. Pauline E. Osamor

Department of Sociology

Bowen University

Iwo, Osun State

Nigeria

Email: ejemenp@yahoo.com able risk factors for cardiovascular diseases (4), treatment that commences once it is recognized reduces the cardiovascular risk of the individual. Therefore, access to treatment with antihypertensive medication and compliance with treatment are key factors in the control of hypertension. Hypertension, the leading cause of mortality and the third largest cause of disability, is poorly controlled worldwide. It is estimated that almost one-half of patients drop out entirely from treatment within one year (5). The failure to control hypertension takes an unacceptable toll on patients and their families. In addition to the personal cost, to the individual patient, uncontrolled hypertension creates huge, avoidable economic burdens when viewed in terms of the general population.

The total number of estimated deaths resulting from all types of cardiovascular diseases and hypertensive heart disease recorded for Nigeria in 2004 
by the World Health Organization (WHO) was 201,500 and 10,700 respectively (6) and placed Nigeria in the 16th position globally. Although these numbers are low compared to 922,700 and 229,000 deaths reported for the USA and the United Kingdom respectively, it is clear that there is a growing health problem that requires an intervention. Uncontrolled blood pressure has been demonstrated to be a major risk factor contributing to more than 500,000 cases of stroke and one million myocardial infarction cases reported each year in the United States alone (7). An estimated 14.55 million people, worldwide, aged 30-80 years, were reported to have died as a result of hypertension-related conditions in 2005 , of which $7.03 \%$ were reported for sub-Saharan Africa (8).

Traditionally, the term compliance has been employed to mean the extent to which the patient, when taking a drug, complies with the clinician's advice and follows the regimen (9). Compliance with treatment is defined and characterized when medical or health advice coincides with the individual's behaviour with regard to the use of medication, recommended changes in lifestyle, and attendance to medical appointments (10). Poor compliance with treatment is the most important cause of uncontrolled blood pressure (11). Results of studies in the United States revealed that long-term compliance with treatment is always a problem in any chronic disease condition, and hypertension is no exception. More than 50\% of patients in the United States, who were prescribed antihypertensive medications actually discontinued therapy within 12 months (12). A common reason given for stopping medication relates to adverse effects, although the patient's knowledge about the disease, attitudes regarding treatment of an often asymptomatic condition, and personal health beliefs, together with cost of medications and availability of healthcare, are major contributors (12).

Multiple factors contribute to poor compliance with long-term antihypertensive therapy. Many patients have negative attitudes towards taking medication, especially if they 'feel well' (13). According to Jadelson et al., the major reasons for non-compliance are multi-factorial and range from lack of adequate guidance to socioeconomic status (14). Although the socioeconomic status has not consistently been found to be an independent predictor of compliance low socioeconomic status may put patients in developing countries in the position of having to choose between competing priorities (15). Such priorities include demands to direct the limited re- source available to meet the needs of other family members, such as children or parents, for whom they care. Some factors reported to have a significant effect on compliance are: poor socioeconomic status (poverty), low level of education, unemployment, lack of effective social support networks, unstable living conditions, long distance from treatment centre, high cost of transport, cultural and lay beliefs about illness and treatment, and forgetfulness (16).

The present study describes treatment-compliance patterns among hypertensive subjects in a Nigerian community and investigates the factors associated with good compliance, including demographic factors, beliefs about hypertension, and the availability of social support.

\section{MATERIALS AND METHODS}

\section{Study design and recruitment of sample}

The study was conducted in the Idikan community, Ibadan, a city in the southwestern Nigeria, as part of a larger community-based study of the sociological aspects of hypertension. Idikan is located in the indigenous part of the city of Ibadan. Idikan is a densely-populated urban community within Ibadan city, with a population of 7,883 (17). Health facilities in the community include an outreach clinic run by the Department of Community Health of the University of Ibadan, a small dental clinic run by the Dental Centre of the University College Hospital (UCH), and private clinics. There are also registered patent medicine stores (pharmacies) and traditional healing homes in the area, all of which are accessible to members of the community.

The study consisted of two components: a quantitative study using a community-based survey of hypertensive subjects and a qualitative study using focus-group discussions (FGDs) on a subset of the participants. The subjects for the quantitative study were adult (aged above 25 years) residents of Idikan who are known to have hypertension. Previous studies in the community had conducted household screening for hypertension, which facilitated the identification of hypertensive subjects in the community. The subjects for this study were selected from a list of known hypertensive subjects residing in the community that was prepared for one such previous hypertension study (18) and was updated for the present study during visits to the home. Four hundred and forty hypertensive subjects were enrolled using a consecutive sampling 
method. The inclusion criteria were: (a) adults aged over 25 years, (b) having diagnosed hypertension by blood-pressure measurements, and (c) awareness of the hypertension status. The only exclusion criteria were refusal to participate and recent (less than three years) diagnosis of hypertension since the study required respondents to have experience living with hypertension to be able to answer the questions. After obtaining informed consent, the subjects were administered a semi-structured questionnaire that had items on several issues, including healthcare-seeking for their hypertension, their beliefs about hypertension, compliance with treatment, and availability of social support (from family and friends).

The goal of the FGDs was to capture in-depth information that is complementary to the quantitative study (survey). This instrument guide had questions on knowledge, beliefs, perceptions, care-seeking behaviour, other experiences, and compliance with treatment for hypertension. Specific probes were included on the reasons (the 'why' and 'how') for the respondent's beliefs, attitude, and actions regarding hypertension they have. Eight FGDs were carried out. A purposive sampling technique was used for selecting participants for group discussion, and discussants were homogeneous in characteristics within each group. There were four groups of males and four groups of females. Each group comprised 6-8 discussants. The inclusion criteria were individuals who were aged 45-60 years. They would have also been diagnosed of high blood pressure for 3-7 years. This allowed for having experiences living with hypertension while minimizing the forgetfulness of care-seeking over time. The key variable reflected in the composition of the focus groups was gender (male vs female). Gender is important because it reflects a major determinant of life experiences of people in the community and to ensure that the discussion and interaction among the participants in the FGDs is free and open. This provided relatively-homogenous focus groups that facilitated free and open discussion on which the amount of information that was elicited depends.

\section{Analysis of data}

Management and analysis of the survey questionnaire data were done using the SPSS software (version 14) (SPSS Inc., Chicago, USA). Frequencies of the responses to the questions were computed and presented as percentages. The association between categorical variables was tested using the chi-square test. Compliance was defined using the question on how frequently people missed taking their medication. Compliance as a variable was defined and used in two ways. First, compliance was scaled as: 'high compliance' (where the respondent 'never misses' or 'rarely misses' to take his/her medication doses); 'medium' compliance (where the respondent 'sometimes' misses taking medication); and 'low compliance' (where the respondent 'regularly' or 'fairly regularly' misses to take his/her medication. These variables were used for identifying the factors associated with compliance in general. Second, since the desired goal of treatment for hypertension is that the patient complies with taking medication for controlling his/her high blood pressure, 'high compliance' (where the respondent never misses or rarely misses to take his/her medication doses) was used for identifying the variables associated with this goal of therapy.

Qualitative data were transcribed as soon as possible after each FGD session. The first author analyzed the qualitative data, reading through all notes and transcripts of the FGDs and identifying emerging themes relating to treatment compliance. Computer-assisted qualitative data analysis (CAQDAS) was also done using the ATLAS.ti software.

\section{Ethical approval}

Ethical approval for the study protocol was obtained from the Institutional Review Committee of the University of Ibadan/University College Hospital, and written informed consent was obtained from all the participants.

\section{RESULTS}

\section{Sociodemographic characteristics}

Of the 440 survey respondents, $65.2 \%$ were women. About half (51.1\%) of the respondents had no formal education. In terms of occupation, $50 \%$ were traders, and about $26 \%$ were retired or not working while $11 \%$ were artisans. The respondents were aged 25-90 years. Their mean age was 60 [standard deviation (SD) 12] years. Dividing the age distribution of the respondents into 10 -year bands, the peak age-categories were 46-55 years and 56-65 years comprising $29.3 \%$ and $29.1 \%$ of the respondents respectively. There was no significant relationship between the gender of the respondents and their age distribution. The large majority (71\%) of the respondents were married (Table 1 ). A large proportion (63.4\%) of the respondents sought care for their condition from a hospital (the University College Hospital, the community health centre, 


\begin{tabular}{|lcc|}
\hline \multicolumn{2}{|c|}{$\begin{array}{c}\text { Table } 1 \text { Demographic characteristics of survey } \\
\text { respondents }(\mathrm{n}=440)\end{array}$} \\
\hline Characteristics & No. & $\%$ \\
\hline Religion & & \\
Islam & 270 & 61.4 \\
Christianity & 169 & 38.4 \\
Traditional & 1 & 0.2 \\
Ethnic group & & \\
Yoruba & 434 & 98.6 \\
Ibo & 5 & 1.1 \\
Isoko & 1 & 0.2 \\
Level of education & & \\
No formal education & 225 & 51.1 \\
Primary & 86 & 19.5 \\
Secondary & 49 & 11.1 \\
Post-secondary & 77 & 17.5 \\
Others (Arabic school) & 3 & 0.7 \\
Occupation & & \\
Trading & 220 & 50.0 \\
Artisanry & 49 & 11.1 \\
Teaching/civil service & 43 & 9.8 \\
Not working (retired) & 113 & 25.7 \\
Religious teaching & 15 & 3.4 \\
\hline
\end{tabular}

or a private hospital) while $5 \%$ visited a chemist or a patent medicine vendor. About $9.5 \%$ of the respondents who visited the hospital also used traditional medicine while $7.3 \%$ visited the chemist and used traditional medicine. None visited a traditional healer exclusively.

\section{Treatment-compliance patterns among respondents}

The findings of the survey showed that $77.5 \%$ of the respondents complied with keeping their follow-up clinic appointments every time. Over onehalf $(50.7 \%)$ of the respondents had high self-reported compliance with treatment as they claimed to be taking their medication regularly whereas $41.5 \%$ had poor self-reported compliance at different levels ranging from regularly missing to take their medication to rarely taking their medication. Forty-six percent had taken their medication on the day of the study.
Eleven percent of the respondents who were noncompliant to medication felt better and, therefore, had no need to continue taking their medication. Other factors included: forgetfulness (8.4\%), lack of funds to purchase drugs $(6.8 \%)$, side-effects of drugs (6.1\%), and having a busy schedule but limited medication (3.6\%). Only $0.5 \%$ said that they were tired of taking drugs. When the respondents perceived forgetting to take medication and sideeffects of treatment as problematic, they were less likely to comply with treatment.

\section{Factors associated with good compliance}

Educational status and religion were two factors that often influenced knowledge, beliefs, attitudes, and practices relating to health and other domains of life. The findings showed that high self-reported compliance was not associated with the religion professed by the respondent. Almost equal percentages of Muslims and Christians (57.8\% vs 59.2\%) showed high self-reported compliance $\left(\chi^{2}=0.797\right.$, $\mathrm{p}=0.671$ ). Concerning education, there was no clear-cut trend with high self-reported compliance $\left(\chi^{2}=6.683, p=0.245\right)$, although those with primary education showed a higher frequency of high self-reported compliance when compared with respondents with other categories of educational levels. Beliefs about the perceived cause of hypertension were not significantly associated with treatment compliance.

There was no association between believing that anxiety or stress is a cause of hypertension and high self-reported compliance. On the other hand, a higher percentage of those whose response to the question on the cause of hypertension was 'Do not know' reported high compliance compared to those who professed to know the cause of hypertension (68.8\% vs 56.2\%) (Table 2). Keeping regular clinic appointments and use/non-use of non-Western medication were significantly $(\mathrm{p}<0.0001)$ associated with high self-reported compliance. Table 3 shows that the respondents who attended clinic appointments 'every time' showed the highest per-

\begin{tabular}{|c|c|c|c|c|}
\hline \multirow{2}{*}{$\begin{array}{l}\text { Perceived cause } \\
\text { of hypertension }\end{array}$} & \multirow{2}{*}{ Response } & \multicolumn{3}{|c|}{ High self-reported compliance } \\
\hline & & No. (\%) & $\chi^{2}$ & $\mathrm{p}$ value \\
\hline Anxiety & $\begin{array}{l}\text { Yes } \\
\text { No }\end{array}$ & $\begin{array}{l}88(56.1) \\
169(59.7)\end{array}$ & 0.559 & 0.455 \\
\hline Stress & $\begin{array}{l}\text { Yes } \\
\text { No }\end{array}$ & $\begin{array}{l}69(62.1) \\
188(57.1)\end{array}$ & 0.861 & 0.354 \\
\hline Do not know & $\begin{array}{l}\text { Yes } \\
\text { No }\end{array}$ & $\begin{array}{l}53(68.8) \\
204(56.2)\end{array}$ & 4.173 & 0.041 \\
\hline
\end{tabular}




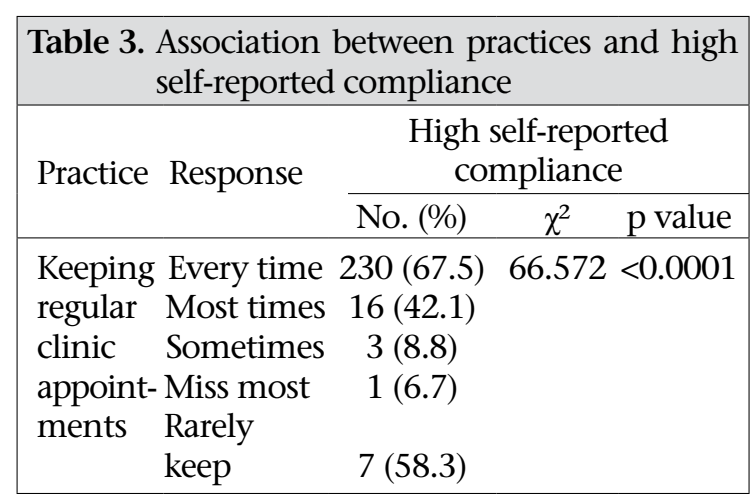

centage (67.5\%) of high self-reported compliance compared to those who attended clinic appointments 'most times' (42.1\%) or less frequently. In other words, regularly keeping clinic appointments
For these analyses, their relationships with compliance in general and with high self-reported compliance (as defined above) were explored. Of the other beliefs about hypertension studied, only the belief that hypertension medication can be stopped after a while was significantly $(\mathrm{p}=0.001)$ associated with compliance in general (Table 4).

Going on to explore the factors associated with high self-reported compliance, the belief that hypertension was curable was significantly $(\mathrm{p}=0.023)$ associated with high self-reported compliance, with $55.6 \%$ of those who said 'Yes' versus $51.6 \%$ of those who answered 'No' and $71.3 \%$ of those who said 'Do not know' showing high self-reported compliance. Also, a lower proportion of those who believed that hypertension medication can be

\begin{tabular}{|c|c|c|c|c|c|c|}
\hline \multirow{2}{*}{$\begin{array}{l}\text { Belief about hyper- } \\
\text { tension }\end{array}$} & \multirow{2}{*}{ Response } & \multicolumn{3}{|c|}{ Compliance (\%) } & \multirow{2}{*}{$\chi^{2}$} & \multirow{2}{*}{$\mathrm{p}$ value } \\
\hline & & High & Medium & Low & & \\
\hline $\begin{array}{l}\text { Hypertension is } \\
\text { preventable }\end{array}$ & $\begin{array}{l}\text { Yes } \\
\text { No } \\
\text { Do not know }\end{array}$ & $\begin{array}{l}57.0 \\
42.1 \\
64.1\end{array}$ & $\begin{array}{l}13.7 \\
31.6 \\
15.6\end{array}$ & $\begin{array}{l}29.4 \\
26.3 \\
20.3\end{array}$ & 8.272 & 0.082 \\
\hline $\begin{array}{l}\text { Hypertension is } \\
\text { curable }\end{array}$ & $\begin{array}{l}\text { Yes } \\
\text { No } \\
\text { Do not know }\end{array}$ & $\begin{array}{l}55.6 \\
51.6 \\
71.3\end{array}$ & $\begin{array}{l}15.8 \\
16.1 \\
11.5\end{array}$ & $\begin{array}{l}28.6 \\
32.2 \\
17.2\end{array}$ & 7.744 & 0.101 \\
\hline $\begin{array}{l}\text { Hypertension is } \\
\text { serious }\end{array}$ & $\begin{array}{l}\text { Yes } \\
\text { No } \\
\text { Do not know }\end{array}$ & $\begin{array}{l}58.2 \\
50.0 \\
65.4\end{array}$ & $\begin{array}{l}14.7 \\
25.0 \\
15.4\end{array}$ & $\begin{array}{l}27.1 \\
25.0 \\
19.2\end{array}$ & 1.778 & 0.777 \\
\hline $\begin{array}{l}\text { Hypertension can } \\
\text { lead to complica- } \\
\text { tions }\end{array}$ & $\begin{array}{l}\text { Yes } \\
\text { No } \\
\text { Do not know }\end{array}$ & $\begin{array}{l}54.5 \\
80.0 \\
55.0\end{array}$ & $\begin{array}{l}14.7 \\
20.0 \\
17.5\end{array}$ & $\begin{array}{c}26.8 \\
0.0 \\
27.5\end{array}$ & 2.106 & 0.716 \\
\hline $\begin{array}{l}\text { Hypertension-relat- } \\
\text { ed complications } \\
\text { can be prevented }\end{array}$ & $\begin{array}{l}\text { Yes } \\
\text { No } \\
\text { Do not know }\end{array}$ & $\begin{array}{l}50.0 \\
60.3 \\
61.0\end{array}$ & $\begin{array}{l}20.7 \\
13.6 \\
14.6\end{array}$ & $\begin{array}{l}29.3 \\
26.2 \\
24.4\end{array}$ & 3.774 & 0.437 \\
\hline $\begin{array}{l}\text { A person on treat- } \\
\text { ment can stop } \\
\text { taking medication } \\
\text { after sometime }\end{array}$ & $\begin{array}{l}\text { Yes } \\
\text { No } \\
\text { Do not know }\end{array}$ & $\begin{array}{l}49.5 \\
60.2 \\
66.7\end{array}$ & $\begin{array}{l}28.3 \\
10.7 \\
14.3\end{array}$ & $\begin{array}{l}22.2 \\
29.1 \\
19.1\end{array}$ & 19.658 & 0.001 \\
\hline
\end{tabular}

was positively associated with high self-reported compliance. In addition, the use of non-Western medication was also significantly related to high self-reported compliance: a significantly lower percentage of those who used non-Western medication showed higher self-reported compliance than those who did not ( $45.3 \%$ vs $63.8 \%$, $\mathrm{p}<0.001)$.

The relationship between beliefs about hypertension may be important to know how well they comply with treatment. These beliefs include the notions that hypertension is preventable, is curable, is a serious condition, and can lead to complications. stopped after a while showed high self-reported compliance $(49.5 \%$ vs $60.2 \%$ of those who answered 'No' and $66.7 \%$ of those who did not know) but this was not significant ( $\mathrm{p}=-0.090)$ (Table 5).

Several potential factors that could affect compliance with treatment, including having a family member with hypertension or who has experienced complications from hypertension, got support from family members and friends were explored in the present project. Most of these factors, including having a family member with hypertension and support from family members and friends, were associated with compliance in gen- 


\begin{tabular}{lccc|}
\hline \multicolumn{3}{l}{ Table 5. Relationships between other beliefs about hypertension and high self-reported compliance } \\
\hline \multirow{2}{*}{ Belief about hypertension } & \multicolumn{3}{c|}{ High self-reported compliance } \\
\cline { 2 - 4 } & 57.0 & 4.004 & $\mathrm{p}$ value \\
\hline Hypertension is preventable & 55.6 & 7.561 & 0.135 \\
Hypertension is curable & 58.2 & 0.877 & 0.023 \\
Hypertension is serious & 58.5 & 1.152 & 0.562 \\
Hypertension can lead to complications & 50.0 & 2.941 & 0.230 \\
$\begin{array}{l}\text { Hypertension-related complications can be prevented } \\
\text { A person on treatment can stop taking medication } \\
\text { after some time }\end{array}$ & 49.5 & 4.812 & 0.090 \\
\hline
\end{tabular}

\begin{tabular}{|c|c|c|c|c|c|c|}
\hline \multirow[b]{2}{*}{ Variable } & \multirow{2}{*}{ Response } & \multicolumn{3}{|c|}{ Compliance (\%) } & \multirow[b]{2}{*}{$\chi^{2}$} & \multirow{2}{*}{$\mathrm{p}$ value } \\
\hline & & High & Medium & Low & & \\
\hline $\begin{array}{l}\text { Has a family member with } \\
\text { hypertension }\end{array}$ & $\begin{array}{l}\text { Yes } \\
\text { No } \\
\text { Do not know }\end{array}$ & $\begin{array}{l}49.3 \\
61.7 \\
45.5\end{array}$ & $\begin{array}{l}23.3 \\
13.5 \\
12.1\end{array}$ & $\begin{array}{l}27.4 \\
24.9 \\
42.4\end{array}$ & 10.146 & 0.038 \\
\hline $\begin{array}{l}\text { Has a family member } \\
\text { who has serious health } \\
\text { problems due to } \\
\text { hypertension }\end{array}$ & $\begin{array}{l}\text { Yes } \\
\text { No } \\
\text { Do not know }\end{array}$ & $\begin{array}{l}36.4 \\
61.2 \\
48.4\end{array}$ & $\begin{array}{c}21.2 \\
14.9 \\
9.7\end{array}$ & $\begin{array}{l}42.4 \\
23.9 \\
41.9\end{array}$ & 12.060 & 0.017 \\
\hline $\begin{array}{l}\text { Family members } \\
\text { concerned about } \\
\text { respondent's hypertension }\end{array}$ & $\begin{array}{l}\text { Not very } \\
\text { concerned } \\
\text { Very } \\
\text { concerned } \\
\text { Extremely } \\
\text { concerned } \\
\text { Do not know }\end{array}$ & $\begin{array}{l}47.6 \\
50.6 \\
61.1 \\
60.0\end{array}$ & $\begin{array}{l}28.6 \\
23.5 \\
\\
11.9 \\
20.0\end{array}$ & $\begin{array}{l}23.8 \\
25.9 \\
27.1 \\
20.0\end{array}$ & 10.857 & 0.093 \\
\hline $\begin{array}{l}\text { Family members helpful } \\
\text { in reminding about } \\
\text { medication }\end{array}$ & $\begin{array}{l}\text { Not very } \\
\text { helpful } \\
\text { Very helpful } \\
\text { Extremely } \\
\text { helpful } \\
\text { Do not know }\end{array}$ & $\begin{array}{l}54.6 \\
48.3 \\
\\
61.5 \\
57.1\end{array}$ & $\begin{array}{l}18.2 \\
27.0 \\
\\
11.5 \\
14.3\end{array}$ & $\begin{array}{l}27.3 \\
24.7 \\
27.0 \\
28.6\end{array}$ & 13.579 & 0.035 \\
\hline $\begin{array}{l}\text { Friends concerned about } \\
\text { respondent's hypertension }\end{array}$ & $\begin{array}{l}\text { Not very } \\
\text { concerned } \\
\text { Very } \\
\text { concerned } \\
\text { Extremely } \\
\text { concerned } \\
\text { Do not know }\end{array}$ & $\begin{array}{l}49.0 \\
50.9 \\
80.3 \\
33.3\end{array}$ & $\begin{array}{c}10.8 \\
27.6 \\
\\
10.2 \\
0.0\end{array}$ & $\begin{array}{c}40.2 \\
\\
21.6 \\
\\
9.5 \\
66.7\end{array}$ & 62.203 & $<0.0001$ \\
\hline $\begin{array}{l}\text { Friends helpful in } \\
\text { reminding about } \\
\text { medication }\end{array}$ & $\begin{array}{l}\text { Not very } \\
\text { helpful } \\
\text { Very helpful } \\
\text { Extremely } \\
\text { helpful } \\
\text { Do not know }\end{array}$ & $\begin{array}{l}49.2 \\
44.0 \\
79.3 \\
50.0\end{array}$ & $\begin{array}{c}12.3 \\
31.9 \\
\\
8.0 \\
25.0\end{array}$ & $\begin{array}{l}38.5 \\
24.2 \\
\\
12.7 \\
25.0\end{array}$ & 62.204 & $<0.0001$ \\
\hline
\end{tabular}

eral. As shown in Table 6, having family members with hypertension and having a family member who has suffered complications were not associated with high self-reported compliance. On the other hand, having friends who were concerned about the respondent's hypertension or who were helpful in reminding the respondent about taking medication was associated with high self-reported compliance.

The findings of the FGD on issues of drug compliance showed that, in general, the respondents 


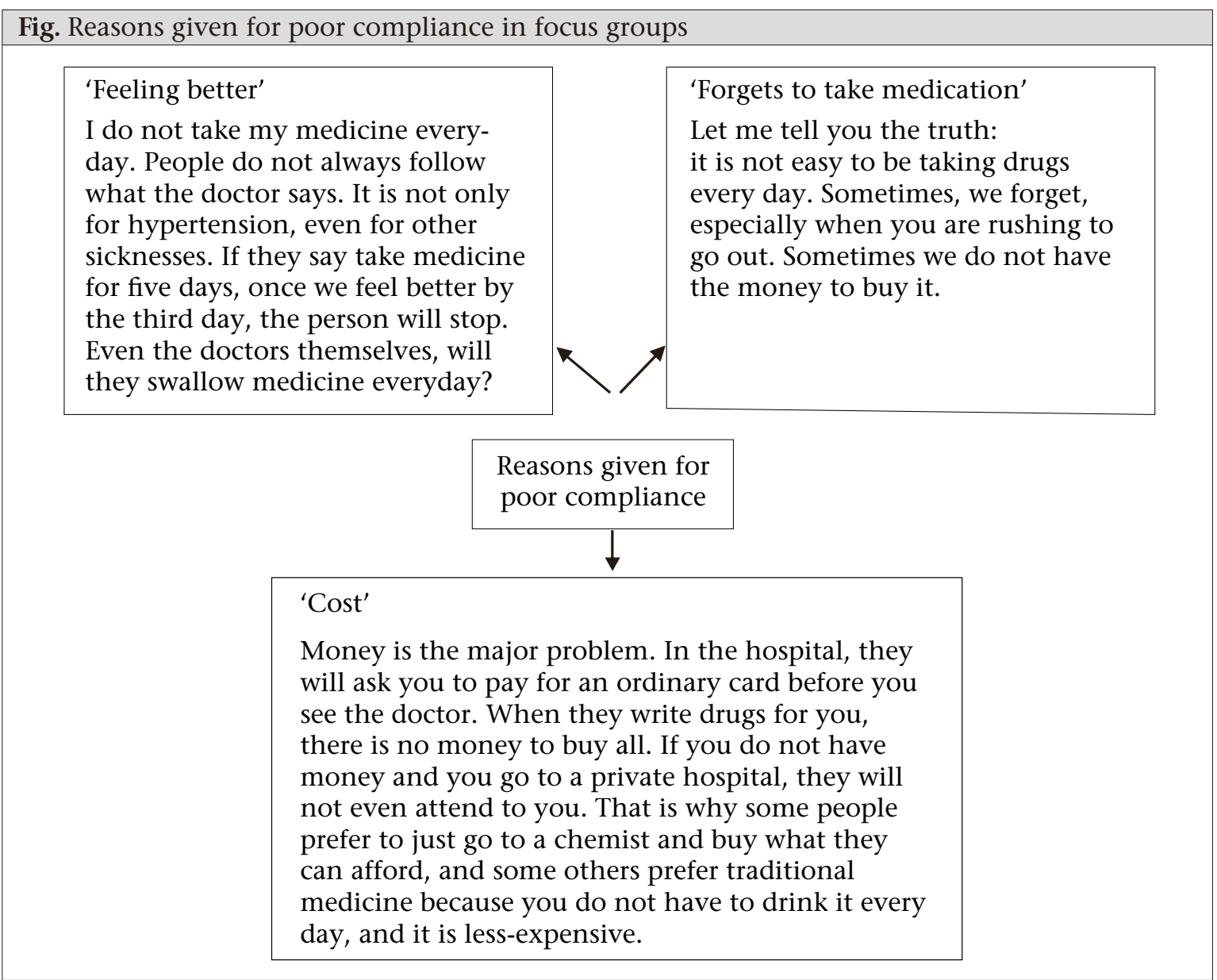

perceived antihypertensive medications to be necessary but indicated those factors that hindered compliance with treatment. The major factors identified in the FGDs included: (a) Costs: medications were expensive compared to income, and some participants could only buy the quantity of medication they could afford instead of the full prescription (for example, two weeks instead of four weeks). This was the factor that was most emphasized; (b) Since having high blood pressure did not make them feel sick, respondents may question the rationale for daily treatment without an end in sight. Even after they became aware of their hypertension and had been on treatment for a while, this rationale persisted, and they often took their medication sporadically and, in some cases, stopped taking their medication after some time; and (c) Difficulty with the idea and practice of taking a medication every day for life. First, the idea of taking a medication daily for life meant that there was no cure, and in any case, many did not see the reason for continuing to take medication when they felt better or their blood pressure was controlled. Second, the participants said that they sometimes forgot to take their medication.
These were the three major themes that emerged from the FGDs. Discussants' quotes that illustrate these obstacles are shown in the Figure.

\section{DISCUSSION}

Compliance with treatment is a very important issue in the successful control of hypertension and prevention of complications. In prescribing medication, compliance usually means "the extent to which the patient takes the medication as prescribed" (19). A number of factors influence compliance. The common belief that patients are solely responsible for taking their treatment is misleading and often reflects a misunderstanding of how other factors affect people's behaviour and capacity to adhere to their treatment.

Belief in the necessity of antihypertensive medication was high among the respondents, and the majority believed that it was necessary to take antihypertensive medication even if one does not feel sick. About $19 \%$ believed that one should only take medication when there are symptoms and had strong concerns about the potential adverse effects of taking medication every day or did not see the 
need for taking medication when one is not feeling ill. This finding also provides a preliminary insight into the mechanism by which beliefs relating to medication might influence compliance. Some of these findings were similar to those reported in previous studies $(20,21)$. Familoni et al., in a 2004 study in Nigeria, reported that only about onethird of patients knew that hypertension should ideally be treated for life, and 58.3\% believed that antihypertensive drugs should be used only where there are 'symptoms' while the remaining 6.3\% believed that the treatment should be for a period of time and not for life (22). Although it has been suggested that it is sometimes possible to withdraw drug therapy and continue lifestyle-modification after several years (23), the consensus is that almost all who are hypertensive before treatment will become hypertensive again if treatment is stopped. This practice has sometimes resulted in disastrous consequences.

There are many concepts that refer to compliance, for example 'compliance', 'adherence', 'commitment', and 'concordance'. According to Kontz, the most important thing is how the content of the concept is defined (24). A major factor accounting for the inadequate treatment of hypertension is poor compliance. The findings of this study revealed that almost half of the respondents reported high compliance with treatment with drug, and 86\% claimed high compliance with keeping their appointments with doctors. Reasons for compliance with treatment include fear of the complications of hypertension and the desire to control blood pressure. Benson, in 2002, reported that patients comply with medication regimen for various reasons, including perceived benefits of medication, fear of complications associated with hypertension, and feeling better on medication (21). The latter reason is contrary to the generally-held belief among physicians that hypertension is a largely asymptomatic disease (25).

Interestingly, about one-half of the study respondents were non-compliant to their medication. The results of the FGDs suggest that the decision to stop using antihypertensive medication is influenced by the beliefs the respondents hold concerning these medications. The identification of the factors determining non-compliance and a better knowledge about them could allow the implementation of measures that could enable their correction and providing the adequate control of blood-pressure levels. In this study, reasons for noncompliance with medication are multifactorial and range from low level of knowledge regarding hypertension as a disease and lack of adequate guid- ance to socioeconomic aspects. The identification of side-effects of treatment used represents another cause of non-compliance with treatment. This finding lays credence to the submission of Hyman and Pavlik that a primary reason given for stopping medication relates to adverse effects, although the patient's knowledge about the disease, attitudes towards treatment of an often asymptomatic condition, and personal health beliefs, together with cost of medications and the availability of healthcare, are major contributors (12). One central theme that runs through the data in this study is the issue of socioeconomic status of the respondents. Financial hardship is a significant barrier to complying with treatment and is a contributory factor to noncompliance. If people are hungry, nothing matters, except food. People either take medication very late when they have had something to eat or forget about it while trying to deal with other problems of poverty. This finding corroborates the observed association among poor compliance, ignorance, and lack of funds for the purchase of drugs reported by Isezuo and Opara (26).

While stress and anxiety were the two most common perceived causes of hypertension among the respondents, the findings showed that those who held these beliefs did not show better compliance than others. However, those who did not know the cause of hypertension showed better compliance with medication than others. This implies that not having preconceived ideas about the cause of hypertension made it more likely that the respondents would comply with treatment. This observation was also common to other beliefs about hypertension (being curable, preventable, serious, leading to complications, and so on) where those who responded 'Do not know' showed a tendency to better compliance. Other studies that have investigated the relationship between beliefs and compliance reported that patient's belief and lack of knowledge, along with other factors, influenced their response to treatment $(27,28)$.

Social support networks are important in the longterm management of chronic conditions, such as hypertension, which requires a radical and life-long change in the lifestyle of the affected person. In the present study, those who had support from friends or family members (concerned about their illness, giving reminders about medication) had better compliance with treatment than those who did not, although this difference was the greatest for those who had the support of friends. This is an important finding and is consistent with what has been reported for multiple chronic diseases in sev- 
eral parts of the world (29). Interestingly, the evidence from the present study shows that support from friends is a stronger factor influencing high self-reported compliance than support from family members. This may be a reflection of the fact that most people in the community (and in cities in general) see, talk, and interact more with their friends than with their family members who do not live nearby. Another explanation may be that those with hypertension are more likely to discuss their health problems with their friends than with their family members, thereby inadvertently limiting the support they could receive from the latter.

\section{Limitation}

A potential limitation of this study is that compliance was measured using self-report and, therefore, suffers from the problems of recall. Inclusion of methods, such as pill-counts or more sophisticated electronic methods, may have helped more accurately assess compliance. However, this was not feasible within the context of a community-based study. Nonetheless, the study provides useful data in this important area of compliance to therapy for a non-communicable disease.

\section{Conclusions}

It is concluded that the control of hypertension is still sub-optimal in this community, with only onehalf of the affected persons reporting high compliance with treatment. The factors associated with high self-reported compliance included: regular clinic attendance, not using non-Western prescription medication, and having social support from family members or friends who were concerned about the respondent's hypertension or who were helpful in reminding the respondent about taking medication. Most respondents believed that hypertension is curable with the use of both orthodox and traditional medicines and that a patient who 'feels well' could stop using antihypertensive medication. On the other hand, specific beliefs about the cause of hypertension were not associated with compliance.

It is recommended that similar research be conducted in developing countries on factors affecting compliance in hypertension and similar diseases that require life-long medication for control. Furthermore, studies are needed on how such findings can be used for guiding local hypertension-control efforts.

\section{ACKNOWLEDGEMENTS}

The authors thank the study participants and leaders of the Idikan community, Ibadan. The input of
Dr. Adebowale Adeyemo of the Center for Research in Genomics and Global Health of the National Institutes of Health, Bethesda, MD, USA, at various stages of the project is hereby acknowledged.

\section{REFERENCES}

1. Kearney PM, Whelton M, Reynolds K, Whelton PK, He J. Worldwide prevalence of hypertension: a systematic review. J Hypertens 2004;22:11-9.

2. Bhatt DL, Steg PG, Ohman EM, Hirsch AT, Ikeda Y, Mas JL et al. International prevalence, recognition and treatment of cardiovascular risk factors in outpatients with atherothrombosis. JAMA 2006;295:180-9.

3. Gunaranthne A, Patel JV, Potluri R, Gill PS, Hughes, EA, Lip GYH. Secular trends in the cardiovascular risk profile and mortality of stroke admissions in an inner-city, multiethnic population in the United Kingdom (1997-2005). J Hum Hypertens 2008;22:1823.

4. United Nations world population projections to 2150. Popul Dev Rev 1998;24:183-9.

5. Chrostowska M, Narkiewicz K. Improving patient compliance with hypertension treatment: mission possible? Curr Vasc Pharmacol 2010;8:804-7.

6. Ayodele OE, Alebiosu CO, Salako BL, Awoden OG, Abigun AD. Target organ damage and associated clinical conditions among Nigerians with treated hypertension. Cardiovasc J S Afr 2005;16:89-93.

7. Gu Q, Burt VL, Paulose-Ram R, Yoon S, Gillum RF. High blood pressure and cardiovascular disease mortality risk among U.S. adults: the third national health and nutrition examination survey mortality follow-up study. Ann Epidemiol 2008;18:302-9.

8. Mathers $\mathrm{CD}$. Uncertainty and data availability for the global burden of disease estimates 2000-2002. Geneva: World Health Organization, 2005. 38 p. (Evidence and information for policy working paper). (http:// www.who.int/healthinfo/publications/boduncertaintypaper2002.pdf, accessed on 14 October 2010).

9. Spencer J, Philips E, Ogedegbe G. Knowledge, attitude, beliefs and blood pressure control in a community-based sample in Ghana. Ethn Dis 2005;15:74852.

10. Wong MC, Jiang JY, Griffiths SM. Factors associated with antihypertensive drug compliance in 83,884 Chinese patients: a cohort study. J Epidemiol Community Health 2010;64:895-901.

11. Burt VL, Whelton P, Roccella EJ, Brown C, Cutler JA, Higgins $\mathrm{M}$ et al. Prevalence of hypertension in the US adult population. Results from the third national health and nutrition examination survey, 1988-1991. Hypertension 1995;25:305-13.

12. Hyman DJ, Pavlik VN. Characteristics of patients 
with uncontrolled hypertension in the United States. N Engl J Med 2001;45:479-86.

13. Hashmi SK, Afridi MB, Abbas K, Sajwani RA, Saleheen D, Frossard PM et al. Factors associated with adherence to anti-hypertensive treatment in Pakistan. PLoS One 2007;2:e280.

14. Andrade JP, Vilas-Boas F, Chagas H, Andrade M. Epidemiological aspects of adherence to treatment of hypertension. Arq Bras Cardiol 2002;79: 375-84.

15. Whitworth JA; World Health Organization, International Society of Hypertension Writing Group. 2003 World Health Organization (WHO)/International Society of Hypertension (ISH) statement on management of hypertension. J Hypertens 2003;21:1983-92.

16. Akpa MR, Agomuoh DI, Odia OJ. Drug compliance among hypertensive patients in Port Harcourt, Nigeria. Niger J Med 2005;14:55-7.

17. Lawoyin TO, Asuzu MC, Kaufman J, Rotimi CN, Owoaje EE, Johnson L et al. Prevalence of cardiovascular risk factors in an African, urban inner city community. West Afr J Med 2002;21:209.

18. Adeyemo AA, Omotade OO, Rotimi CN, Luke AH, Tayo BO, Cooper RS. Heritability of blood pressure in Nigerian families. J Hypertens 2002;20:859-63.

19. Fawcett J. Compliance: definitions and key issues. J Clin Psychiatry 1995;56(Suppl 1):4-8.

20. Gascón JJ, Sánchez-Ortuño M, Llor B, Skidmore D, Saturno PJ; Treatment Compliance in Hypertension Study Group. Why hypertensive patients do not comply with the treatment: results from a qualitative study. Fam Pract 2004;21;125-30.
21. Benson J, Britten N. Patients' decisions about whether or not to take antihypertensive drugs: qualitative study. Br Med J 2002;325:873.

22. Familoni BO, Ogun SA, Aina AO. Knowledge and awareness of hypertension among patients with systemic hypertension. JAMA 2004;96:620-4.

23. Salako LA. Treatment of hypertension. In: Cardiovascular diseases in Africa. Gauteng: Ciba Geigy Ltd., 1979:22-7.

24. Kontz MM. Compliance redefined and implications for home care. Holist Nurs Pract 1989;3:54-64.

25. Dosse C, Cesarino CB, Martin JF, Castedo MC. Factors associated to patients' noncompliance with hypertension treatment. Rev Lat Am Enfermagem Março 2009;17:201-6.

26. Isezuo AS, Opera TC. Hypertension awareness among Nigerians in a Nigerian tertiary health institution. Sehel Med J 2000;3:93-6.

27. James H. A study of seventy diabetic and hypertensive patients attending the medical out patients clinic at the Spanish town hospital St. Catherine. Kingston: University of the West Indies, 1978. (Unpublished Diploma thesis).

28. Wang PS, Bohn RL, Knight E, Glynn RJ, Mogun H, Avorn J. Noncompliance with antihypertensive medications: the impact of depressive symptoms and psychosocial factors. J Gen Intern Med 2002;17:504-11.

29. Oxman TE, Hull JG. Social support and treatment response in older depressed primary care patients. $J$ Gerontol B Psychol Sci Soc Sci 2001;56:P35-45. 